TP Periodica Polytechnica

Social and Management Sciences

22(2), pp. 99-106, 2014

DOI: $10.3311 /$ PPso. 7377

Creative Commons Attribution (i)

RESEARCH ARTICLE

\section{The Sectoral Adaptive Capacity Index of Hungarian Road Transport}

Gábor Szendrő / Mária Csete / Ádám Török

RECEIVED 25 February 2014; ACCEPTEd AFter REVISION 27 MARCH 2014

\section{Abstract}

The understanding of different adaptive capacities is a prerequisite for targeting interventions aiming to reduce the adverse effects of climate change. Indicators and indices are common tools in this process, but their construction is fraught with many uncertainties. This paper aims to investigate the application of the Adaptive Capacity Index applied to the road transport sector. Authors sought to describe the effects of climate change on road transport and have modeled its adaptive capacity as a probability function of a combination of variables. The authors have designed and created the Sectoral Adaptive Capacity Index for the Hungarian transport sector, and investigated the trends in the historical data series of this indicator.

\section{Keywords}

environmental sustainability $\cdot$ road transport $\cdot$ indicators $\cdot$ climate change $\cdot$ vulnerability $\cdot$ sectoral adaptive capacity index

\section{Gábor Szendró}

Department of Environmental Economics, Budapest University of Technology and Economics, Magyar Tudósok krt. 2., H-1117 Budapest, Hungary e-mail: szendro@eik.bme.hu

\section{Mária Csete}

Department of Environmental Economics, Budapest University of Technology and Economics, Magyar Tudósok krt. 2., H-1117 Budapest, Hungary e-mail: csete@eik.bme.hu

\section{Ádám Török}

Department of Transport Technology and Economics, Budapest University of Technology and Economics, Sztoczek u. 2., H-1111 Budapest, Hungary e-mail: atorok@kgazd.bme.hu

\section{Introduction}

Transportation is a mission-critical area in the economic sector around the world, contributing to development and progress by creating and maintaining jobs, also generating a considerable portion of GDP. The other side of the coin is that the current transportation systems in Hungary and around the world create externalities, pollution, and unsustainable operation. The decline in natural ecosystems caused by pollution, if not addressed, could eventually manifest as an economic loss, creating a major incentive for intervention in addition to conservation. Climate change and transport related emission is being widely recognized as a major issue of the 21 st century all over the world (Koetse, Rietveld, 2009; Al-Mofleh et al., 2010; Beškovnik, Twrdy, 2012; Rao, Rao, 2012; Vaiškūnaitè, 2012, Csefalvay et al., 2014). The Intergovernmental Panel on Climate Change has concluded that anthropogenic greenhouse gas emissions will continue to be a driver of climate change in the future. The projected impacts are likely to require adaptation actions to minimize adverse impacts. Over time, multiple avenues have been explored to address the issues related to transport-related emissions, approaching the problem from the policy and technological side. Most technology-based solutions (e.g. alternative fuels and propulsion methods such as biodiesel, bioethanol, etc.) have only proven to be partially effective, their benefits cancelled out by the sheer growth in demand. One of the most recent policy documents in the EU of this sort is the White Paper on Transport, which sets a number of objectives, including the following (White Paper on Transport, 2011):

1. $60 \%$ cut in GHG emissions from transportation by 2050 on a 1990 base

2. Intermediate goal for 2030 is a $20 \%$ cut in GHG emissions by 2030 on a 2008 base (technically $8 \%$ above 1990 levels)

3 . Improving efficiency through improved traffic management and information systems

4. Shifting $30 \%$ of road freight over $300 \mathrm{~km}$ to rail by 2030

5. Halve the use of conventional (i.e. internal combustion engine) cars by 2030, phase them out in cities completely by 2050 


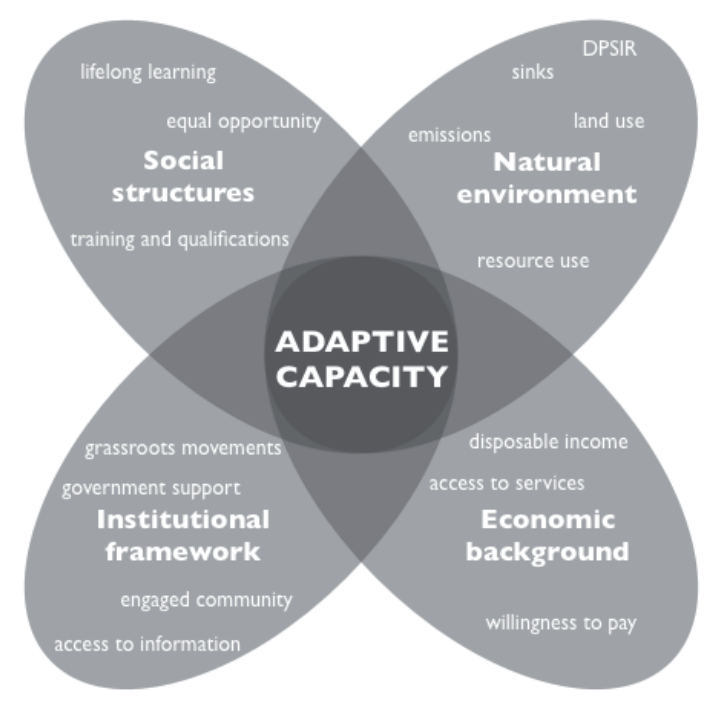

Fig. 1. Factors in adaptive capacity (Tostovrsnik et al., 2010)

Changes in EU policies also bring new challenges. As EU Climate Commissioner Connie Hedegaard stated in October 2012: first generation biofuels are "not the future of Europe". This new line of thinking originates from issues such as ethical dilemmas, the food vs. fuel debate, indirect land use changes, and the destruction of carbon sinks in developing countries, etc., extensively discussed in literature (Astbury, 2008; Baka, Roland-Holst, 2009; Yeh, Sperling 2010; Harvey, Pilgrim, 2011; Kivevele et al., 2011; Barabas, Todorut, 2012; Kuchler, Linnér, 2012; Lebedevas et al., 2012; Chollacoop et al., 2013) and many others. These developments have made it clear that demand management and adaptation will have a greater role going forward.

According to the IPCC, adaptive capacity "is the ability or potential of a system to respond successfully to climate variability and change, and includes adjustments in both behaviour and in resources and technologies" (IPCC, 2007). One of the most interesting questions is how public policy can react to sectoral adaptation research and the solutions it provides (Dovers, Hezri, 2010; Eisenack, 2012; Larsen et al., 2012; Reyer, 2012; Romero-Lankao, 2012; Techner et al., 2012; Uhlik et al., 2012; Csete et al., 2013; Scrieciu et al., 2013). Analyzing adaptive capacity is fraught with uncertainties, since forecasts are necessary to determine whether adaptive capacity assets will be utilized if the need arises.

Adaptive capacity is multidimensional: it is a function of social, political, economic, technological and institutional factors (see Fig. 1).

The interactions between these factors are complex and occur on multiple levels (national, regional, local, individual). Finding accurate and reliable indicators and data sources and determining the direction of relationships is difficult, making quantification efforts questionable. Even so, quantification remains an important element in policymaking, being one of the few ways adaptive capacity can be presented to decision makers. The aim of this paper is to highlight the uncertainties of measuring adaptive capacity.

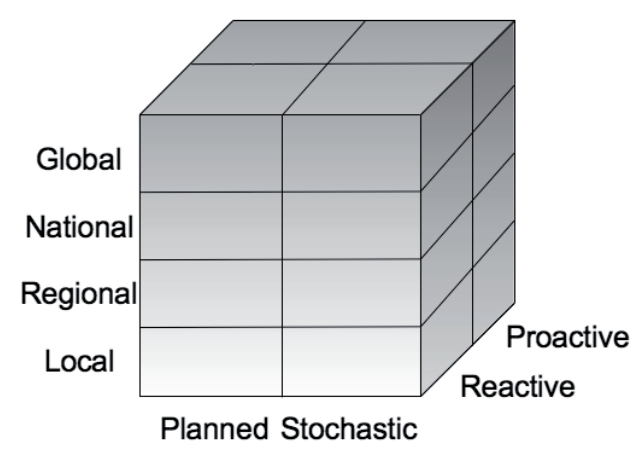

Fig. 2. Possible attributes of adaptation strategies

\section{The model - defining adaptive capacity and the sectoral adaptive capacity index}

There are many definitions describing the concept of adaptation, most revolve around the capacity to endure and adjust to changes in our environment. Berrang-Ford et al., (2011) defines adaptation as "adjustments in ecological-socio-economic systems in response to actual or expected climatic stimuli, their effects or impacts", with respect to climate change. Pielke (1998), also in the context of climate change, defines adaptation as the "adjustments in individual groups and institutional behaviour in order to reduce society's vulnerability to climate." Brooks et al., (2005) describes adaptation as "adjustments in a system's behaviour and characteristics that enhance its ability to cope with external stress".

The types of adaptation can be defined based on spontaneity (planned vs. autonomous) and proactivity (reactive vs. anticipatory) Berrang-Ford et al., (2011).

The concepts of adaptation, adaptive capacity, vulnerability, resilience, exposure and sensitivity are interrelated and have global implications. The vertical axis of Fig. 2. shows the possible intervention levels of adaptation policies with respect to the different territorial dimensions in a top-down approach: global, national, regional, local levels The horizontal axes include two further considerations - showing the nature of interventions (planned vs. ad-hoc), and the dynamics (proactive vs. reactive). These parameters may be found in any combination, and are descriptive of adaptation strategies.

The adaptation of the transport sector to a particular climate stress such as drought is determined by the vulnerability and adaptation of a community to multiple stresses, and, on a larger scale, by the vulnerability of mankind (or the global ecosystem) to all stresses and forces. Applications also vary by the area of interest (biological, economic, social, etc.), and by time scale (instantaneous, months, years, decades, centuries). This paper aims to investigate the application of the adaptive capacity index on the road transport sector.

The term adaptation was originally conceived to describe processes in biology (evolution). In anthropology and archaeology, adaptation is the result of a selection process, enabling the survival of a given species or culture (O’Brien, Holland, 1992). 
The definition of adaptation in the evolutionary scope differs little from what adaptation is understood to be when applied to climate change: the development of (genetic, behavioral, etc.) characteristics which enable organisms or systems to cope with environmental changes in order to survive and reproduce (Kitano, 2002).

Vincent (2007) provides another definition: adaptive capacity is essentially "a vector of resources and assets that represents the asset base from which adaptation actions and investments can be made". The uncertainties already discussed apply here as well: the actual utilization of adaptive capacity cannot be taken for granted and is determined by different variables. Nevertheless, quantified adaptive capacity remains an important indicator describing the capabilities and needs of different sectors and assessing the effects of climate change. Considering net impacts, often called end point vulnerability (O'Brien et al., 2004), the effects of climate change stem from the following: exposure to climate risks or hazards, the sensitivity of the ecosystem and social environment to that exposure, and adaptive capacity. Therefore, adaptive capacity is a component of vulnerability (Berrang-Ford et al., 2011; Tubi et al., 2012). The IPCC assessments state that adaptive capacity is determined by "the characteristics of communities, countries and regions that influence their propensity or ability to adapt" (IPCC, 2007). In the present paper, authors are analyzing the vulnerability and adaptive capacity of the Hungarian road transport sector, seeking to describe the effects of climate change on road transport and creating a model for road transport adaption potential as a probability function of a combination of determinant probabilities.

Based on Hungarian (Szendrő et. al., 2012) and international literature (Pérez-Martínez, 2012), the following indicators have been selected for further analysis:

- Fossil fuel consumption (warming in the Hungarian weather increases consumption from the use of $\mathrm{A} / \mathrm{C}$ systems and will decrease the Sectoral Adaptive Capacity Index -winter fuel consumption will not decrease so long as the waste heat of the engine is used for heating the vehicle),

- The total length of Hungarian motorway system (increased winter precipitation decreases the Sectoral Adaptive Capacity Index - more intensive use of snow plows increases pothole damage),

- The number of registered vehicles in Hungary (the number of vehicle correlates with vulnerability - increased frequency of extreme weather events decrease the Sectoral Adaptive Capacity Index),

- The Human Development Index (increasing HDI will decrease the impacts of climate change on the transport sector and will increase the Sectoral Adaptive Capacity Index).

Authors used a Gaussian normal distribution of probability function and the Chebyshev-estimation method of determinants over time for forecasting (Fig. 3. and Fig. 4.).

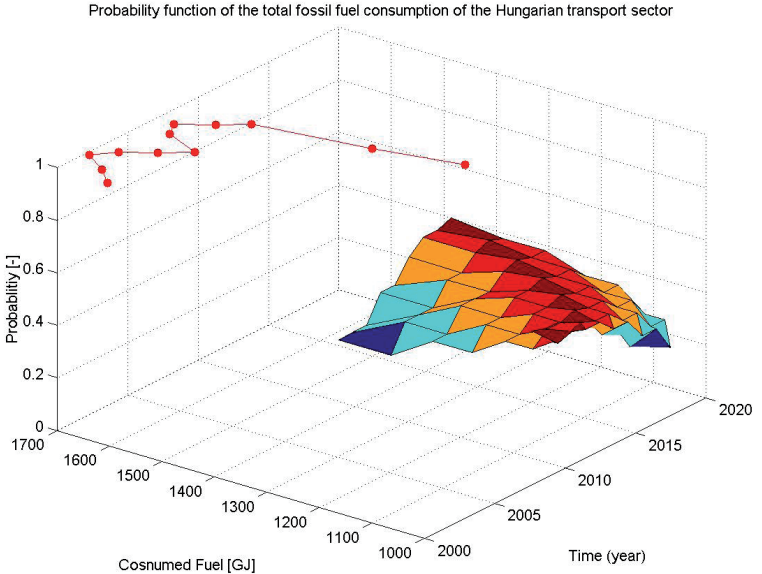

Fig. 3. Probability function example - the length of the motorway system

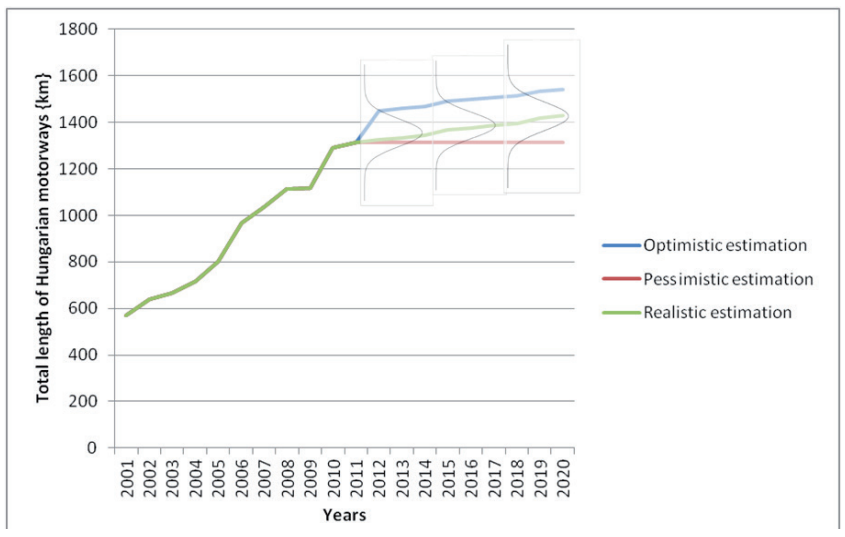

Fig. 4. Probability function example - fuel consumption

$$
\bar{d}_{i}=\left\{\begin{array}{c}
\left|\begin{array}{c}
x_{0} \\
x_{1} \\
x_{t}
\end{array}\right|, \text { if } t \leq 2011 \\
\left|\begin{array}{c}
x_{t+1}\left(\mu_{t+1} ; \sigma_{t+1)}\right) \\
x_{t+n}\left(\mu_{t+n} ; \sigma_{t+n}\right) \\
x_{2020}\left(\mu_{2020} ; \sigma_{2020}\right)
\end{array}\right|_{t} \text {,if } t>2011
\end{array}\right.
$$

where:

$d$ is the vector of resource $\mathrm{i}$

$x$ is the value of resource (deterministic before 2012 and probability-based after 2011)

$i$ is the number of different resources

$t$ is the year of investigation

It is important to note that the institutional context has considerable effect on adaptation (this may be a barrier or a driver), and it "mediates the access to individual or household adaptation opportunities" (Pelling, High, 2005). The driving forces behind adaptive capacity can vary. Referring back to uncertainties again, it is understood that existing adaptive capacity may only become visible when exposure to the effects of climate change occurs (latent adaptive capacity) (IPCC, 2007). The expectation that impacts of climate change may occur can induce anticipatory adaptive capacity, which reflects the 
proactive approach necessary for effective mitigation measures. However, measuring anticipatory adaptive capacity is quite challenging.

When creating the indicators to be used, the authors have considered aggregate (where components are not recognizable), and composite indices. The indices presented here are of both kinds: the final index is an aggregate, but is made up of a number of composite, non-linear, disjoint, sub-indices. The time scale element is a particular cause of uncertainty when trying to determine adaptive capacity. As outlined above, adaptive capacity is multi-dimensional and is determined by a variety of parallel processes. It is impossible to represent the inter-relationships between different determinants or driving processes that interact in different ways, according to the temporal and spatial scale of analysis (Füssel, 2010). Thus, to reduce further uncertainty in the prediction, both indices present current snapshots of adaptive capacity. Clearly, there is a degree contradiction in using a current measure when looking at climate change in the future.

In addition to the issue of how driving forces will change over time, using current adaptive capacity also raises questions over how to validate the effectiveness of indicators. One of the main reasons for this uncertainty is not being able to validate the effectiveness of the indicators in representing determinants of adaptive capacity, as indeed the whole objective of indicators is to capture intangible processes. Some indicators assess their validity through correlations with past disaster data (Brooks et al., 2005; Easter, 1999; Pelling, Uitto, 2001; Etter et al., 2011). But this method is less than ideal as it too is working across timescales, linking current vulnerability to past events (Fig. 5).

\section{Measuring the adaptive capacity of the Hungarian road transport sector}

Calculating the Sectoral Adaptive Capacity Index for the Hungarian transport sector started with the cross-correlation of selected data series. Our findings show that there is considerable cross-correlation, therefore, these parameters cannot be used in our model as independent variables. The authors have decided to investigate only GDP and fuel consumption further. Eq. (2) outlines the structure of SACI, showing the composite sub-indices and their component indicators.

$$
C_{t}=\sum_{i=1}^{n}\left(w_{i ; t} \cdot d_{i ; t}\right)
$$

where:

$C_{t}$ is the adaptive capacity index at year $t[-]$

$w_{i, t}$ is the weight of determinant $i$ at year $t$

$d_{i}$ is determinant $i$ at year $t$

At the sectoral level, adaptation potential is determined by a range of different factors such as managerial ability, access to financial, technological and information resources,

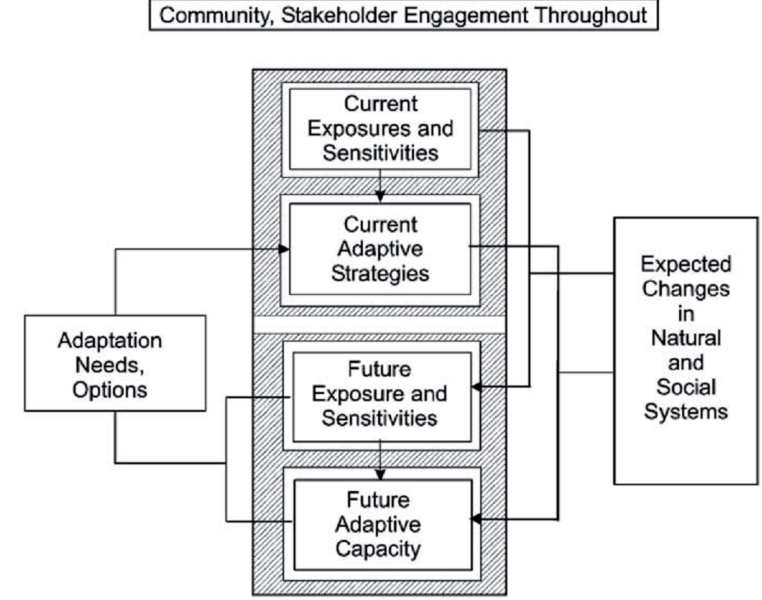

Fig. 5. Conceptual framework for vulnerability assessment and mainstreaming (Smit, Wandel, 2006)

infrastructure, the institutional environment of adaptation, political influence, kinship networks, etc. (Adger et al., 2005; Heltberg et al., 2009; Haines, 2012)

The purpose of this study is to develop indicators on the national level for assessing vulnerability and the capacity to adapt to climate change impacts. Currently, large amounts of $\mathrm{CO}_{2}$ are emitted globally. With its connection to radiative forcing, $\mathrm{CO}_{2}$ is one of the main global polluters with no responsibility and control loop in this system in order to reduce emissions. Eq. (3) shows the correlation between $\mathrm{CO}_{2}$-concentration and radiative forcing.

$$
\Delta F=535 \times \ln \frac{C}{C_{0}}\left[W / m^{2}\right]
$$

where:

$\mathrm{F}$ is radiative forcing in $\mathrm{W} / \mathrm{m}^{2}$

$\mathrm{C}$ is the atmospheric concentration of $\mathrm{CO}_{2}$ in $\mathrm{ppm}$

$\mathrm{C}_{0}$ is the reference concentration of $\mathrm{CO}_{2}$ in ppm

Although determining vulnerability is fraught with uncertainty as described above, empirical studies and analyses could provide invaluable inputs to policy. It is also true that sensitivity and exposure have been researched more extensively in the past than adaptive capacity. There has been increasing focus in the climate change policy process in recent years (Tanczos et al., 2011) on the potential for adaptation. Adaptive capacity is a useful tool for determining strong and weak points in resilience to climate change, especially when sectoral data for the same country are compared. Through the comparison, sectors of intervention (with weak adaptive capacity) can be identified where policy efforts need to be concentrated. There are two different ways to approach this issue: data-driven and theorydriven. Many indicators and index studies on the subject are data-driven. The authors have combined the two approaches with probability based data-driven theory and used a Gaussian normal distributed data estimated with the Chebyshev method. 
The data-driven approach selects from a wide range of different indicators based on expert judgment (Kaly, Pratt, 2000), principle components analysis (Easter, 1999), or correlation with past disaster events (Brooks, 2005) based on the proportion of vulnerability the given indicators account for, creating a need to use a proxy variable for benchmarking prospective indicators. The theory-driven approach, on the other hand, selects the indicators to be used based on theory (the availability of data remains a constraint for this approach as well) (Kriegler, 2012). It is also necessary for the chosen indicators to accurately represent the driving force and have construct validity.

The authors have used the probability function of such indicators. The third source of uncertainty when it comes to indicators related to adaptive capacity is determining the direction of the relationship between the indicator and adaptive capacity. Lastly, the effects of governance need to be discussed, as they are not always intuitive and the goals and objectives are often not known. This may lead to an unfavorable practice of placing greater emphasis on short-term thinking and investments in averting short-term impacts. Weighting can vary over space, time, and sectors, this article concentrates on the Hungarian road transport sector. Probability functions have been used in order to deal with dynamic uncertainties over time. Obtaining national-level sectoral data may require averaging due to considerable differences on the sub-national level.

The determinants of adaptive capacity are interrelated, and therefore cannot be isolated: the interaction of different variable determinants forms adaptive capacity. Consensus or widespread support has not yet been reached for a specific model that describes local exposure, sensitivity, and adaptive capacity.

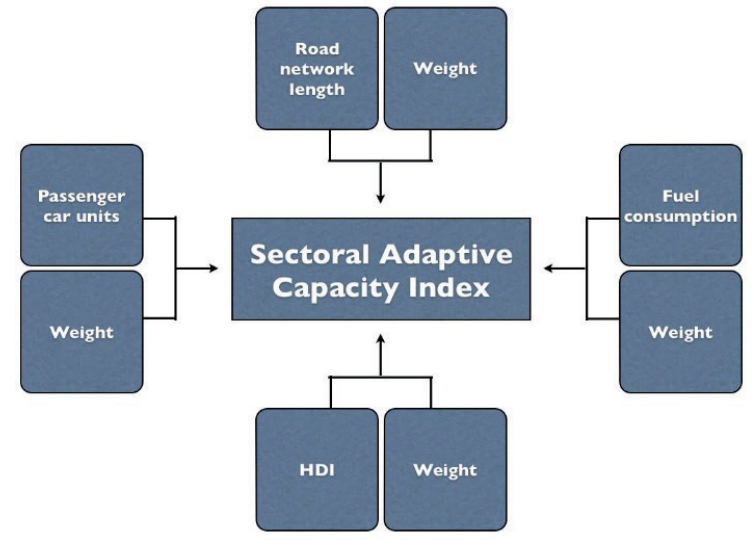

Fig. 6. Conceptual framework of the sectoral adaption capacity index

The model presented in this paper has been designed to avoid cross correlation (through the choice of determinants) and to use a top-down methodology.

Based on previous work and own judgment, the authors have identified a shortlist of 4 variables representing generic vulnerability in the road transport sector, describing social awareness, physical infrastructure, and technological capacity. The neural network of the Sectoral Adaptive Capacity Index can be seen on Fig. 6 .

The reason for performing such a calculation is to get an overall picture of the adaptive capacity of a given sector in order to identify points of intervention where action can be taken to effectively reduce vulnerability and decrease exposure.

Once the data is thusly compiled, the time series of the SACI index can be visualized (Fig. 7).
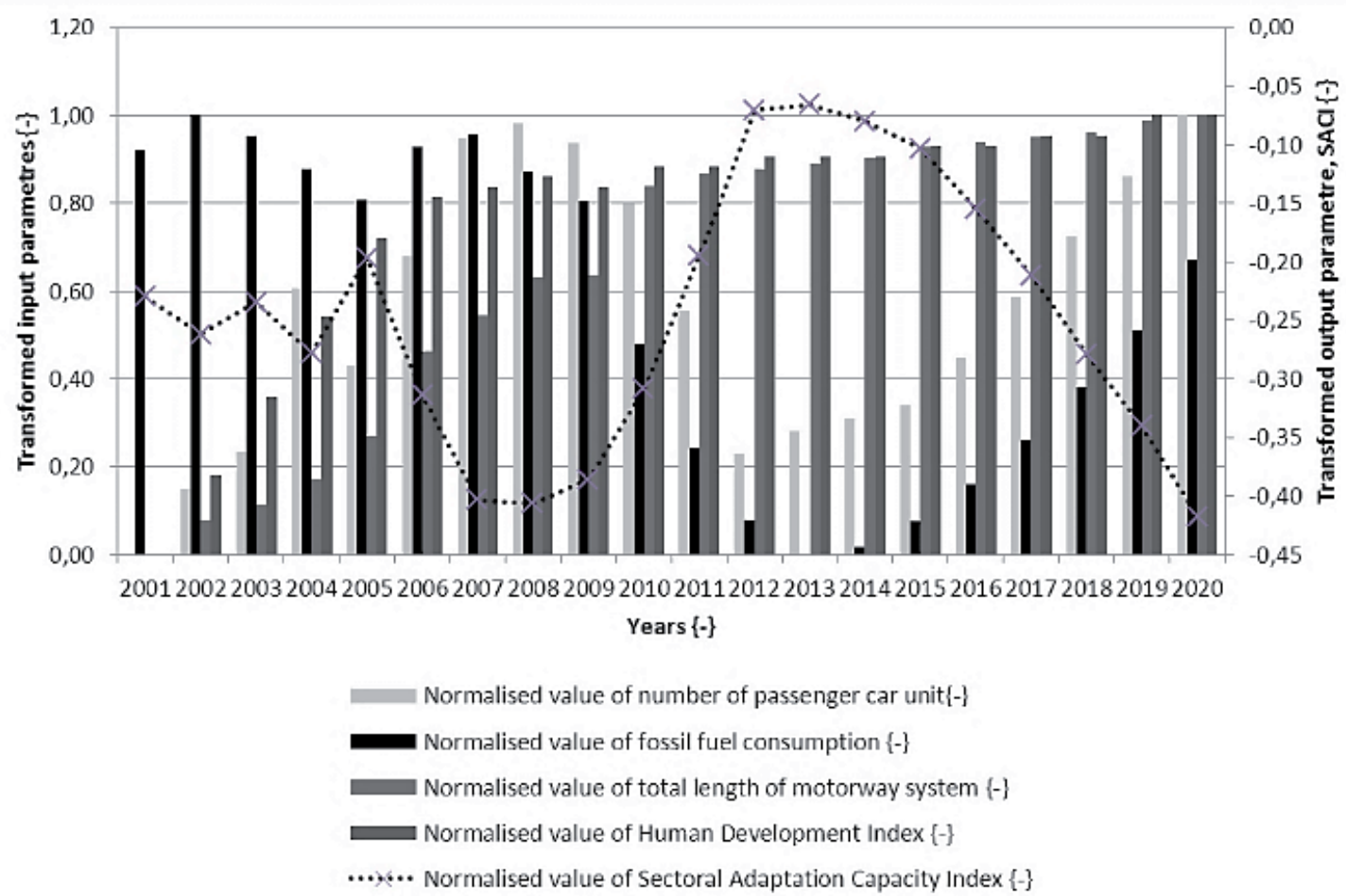

Fig. 7. Composition and time series of SACI 
Tab. 1. Results of the Sensitivity Analysis (How changes of input parameters influence SACI)

\begin{tabular}{|c|c|c|c|c|c|c|c|c|c|}
\hline Year & $\begin{array}{l}\text { Base of } \\
\text { analysis }\end{array}$ & $\begin{array}{c}\text { PCU weight } \\
+10 \%\end{array}$ & $\mathrm{PCU}+10 \%$ & $\begin{array}{l}\text { FC weight } \\
\quad+10 \%\end{array}$ & $\mathrm{FC}+10 \%$ & $\begin{array}{l}\text { HDI weight } \\
\quad+10 \%\end{array}$ & $\mathrm{HDI}+10 \%$ & $\begin{array}{c}\text { Length } \\
\text { weight } \\
+10 \%\end{array}$ & $\begin{array}{r}\text { Length } \\
+10 \%\end{array}$ \\
\hline 2001 & $-0,23$ & $-0,23$ & $-0,25$ & $-0,32$ & $-0,26$ & $-0,23$ & $-0,20$ & $-0,23$ & $-0,25$ \\
\hline 2002 & $-0,26$ & $-0,28$ & $-0,29$ & $-0,36$ & $-0,29$ & $-0,24$ & $-0,24$ & $-0,27$ & $-0,29$ \\
\hline 2003 & $-0,23$ & $-0,26$ & $-0,26$ & $-0,33$ & $-0,26$ & $-0,20$ & $-0,21$ & $-0,25$ & $-0,26$ \\
\hline 2004 & $-0,28$ & $-0,34$ & $-0,30$ & $-0,37$ & $-0,30$ & $-0,22$ & $-0,25$ & $-0,30$ & $-0,30$ \\
\hline 2005 & $-0,20$ & $-0,24$ & $-0,22$ & $-0,28$ & $-0,22$ & $-0,12$ & $-0,17$ & $-0,22$ & $-0,22$ \\
\hline 2006 & $-0,31$ & $-0,38$ & $-0,34$ & $-0,41$ & $-0,34$ & $-0,23$ & $-0,29$ & $-0,36$ & $-0,34$ \\
\hline 2007 & $-0,40$ & $-0,50$ & $-0,43$ & $-0,50$ & $-0,43$ & $-0,32$ & $-0,38$ & $-0,46$ & $-0,43$ \\
\hline 2008 & $-0,41$ & $-0,50$ & $-0,43$ & $-0,49$ & $-0,43$ & $-0,32$ & $-0,38$ & $-0,47$ & $-0,43$ \\
\hline 2009 & $-0,39$ & $-0,48$ & $-0,41$ & $-0,47$ & $-0,41$ & $-0,30$ & $-0,36$ & $-0,45$ & $-0,41$ \\
\hline 2010 & $-0,31$ & $-0,39$ & $-0,33$ & $-0,36$ & $-0,33$ & $-0,22$ & $-0,28$ & $-0,39$ & $-0,33$ \\
\hline 2011 & $-0,19$ & $-0,25$ & $-0,22$ & $-0,22$ & $-0,22$ & $-0,11$ & $-0,17$ & $-0,28$ & $-0,22$ \\
\hline 2012 & $-0,07$ & $-0,09$ & $-0,10$ & $-0,08$ & $-0,10$ & $-0,02$ & $-0,04$ & $-0,16$ & $-0,10$ \\
\hline 2013 & $-0,07$ & $-0,09$ & $-0,09$ & $-0,07$ & $-0,09$ & $-0,02$ & $-0,04$ & $-0,16$ & $-0,09$ \\
\hline 2014 & $-0,08$ & $-0,11$ & $-0,11$ & $-0,08$ & $-0,11$ & $-0,01$ & $-0,05$ & $-0,17$ & $-0,10$ \\
\hline 2015 & $-0,10$ & $-0,14$ & $-0,13$ & $-0,11$ & $-0,13$ & $-0,01$ & $-0,08$ & $-0,20$ & $-0,13$ \\
\hline 2016 & $-0,15$ & $-0,20$ & $-0,18$ & $-0,17$ & $-0,18$ & $-0,06$ & $-0,13$ & $-0,25$ & $-0,18$ \\
\hline 2017 & $-0,21$ & $-0,27$ & $-0,24$ & $-0,24$ & $-0,24$ & $-0,12$ & $-0,19$ & $-0,31$ & $-0,24$ \\
\hline 2018 & $-0,28$ & $-0,35$ & $-0,30$ & $-0,32$ & $-0,30$ & $-0,18$ & $-0,25$ & $-0,37$ & $-0,30$ \\
\hline 2019 & $-0,34$ & $-0,43$ & $-0,36$ & $-0,39$ & $-0,37$ & $-0,24$ & $-0,32$ & $-0,44$ & $-0,37$ \\
\hline 2020 & $-0,42$ & $-0,52$ & $-0,44$ & $-0,48$ & $-0,44$ & $-0,32$ & $-0,39$ & $-0,52$ & $-0,44$ \\
\hline
\end{tabular}

(source: own calculation)

*Note: Base of analysis is when the decision weights are equal. Passenger car unit weight is $+10 \%$ when the decision weight of passenger car is increased by $10 \%$. Passenger car unit is $+10 \%$ when the number of passenger car is increased by 10\%. Fuel cost weight is $+10 \%$ when the decision weight of fuel cost is increased by $10 \%$, and so forth. Sensitivity increases from lighter to darker grey.

The correlation between changes in the global economy and the time series data of SACI are clear: the Sectoral Adaptive Capacity Index appears to be inversely correlated with the general state of the economy, suggesting that consumers are willing to explore alternative forms of mobility in case their financial situation become less advantageous. In order to understand these results better, a sensitivity analysis for the input parameters must also be carried out (Table 1).

\section{Conclusions}

The authors have designed and created the Sectoral Adaptive Capacity Index (SACI) for the Hungarian road transport sector. The data series and estimations were normalized to achieve comparability between data sets. Values were transformed to $[0 \ldots 1]$ interval (normalization was not suitable for the transformed input parameters, as it could result in negative values) and then weighted and presented together (Fig. 7).

As it can be seen in Fig. 7, the composed sectoral adaptive capacity index shows a clear and significant correlation with the economic crisis. Up until 2007, the sectoral adaptation potential has been decreasing due to increasing fossil fuel consumption, the extension of the road network and the increasing number of passenger cars in the system. These resulted in an increased vulnerability of the sector.

From 2007 to 2013, the decreasing number of passenger cars and decreasing fossil fuel consumption led to an increased sectoral adaptive capacity index for the Hungarian transport sector, leading us to believe that the vulnerability of the system has been reduced due to the economic crisis (note that the scale for SACI is reversed).

In order to understand such a phenomenon, further investigation will be required. For projections of future data points, the authors have estimated an increase in fossil fuel consumption, increasing number of passengers and a slowing extension of the road network. Authors have investigated the SACI model itself and conducted a sensitivity analysis with the input probability functions. (Results are shown in Table 1.) 


\section{Acknowledgement}

This paper was supported by the János Bolyai Research Scholarship of the Hungarian Academy of Sciences.

\section{References}

Adger W. N., Arnell N. W., Tompkins E. L. (2005) Successful adaptation to climate change across scales. Global Environmental Change, 15 (2), pp. 77-86.

DOI: $10.1016 /$ j.gloenvcha.2004.12.005

Al-Mofleh A., Taib S., Salah W. A. (2010) Malaysian energy demand and emissions from the transportation sector. Transport, 25 (4), pp. 448-453. DOI: $10.3846 /$ transport.2010.55

Astbury G. R. (2008) A review of the properties and hazards of some alternative fuels. Process Safety and Environmental Protection, 86 (6), pp. 397-414.

DOI: $10.1016 /$ j.psep.2008.05.001

Baka J., Roland-Holst D. (2009) Food or fuel? What European farmers can contribute to Europe's transport energy requirements. Energy Policy, 37 (7), pp. 2505-2513. DOI: $10.1016 /$ j.enpol.2008.09.050

Barabas I., Todorut I-A. (2012) Predicting the temperature dependent viscosity of biodiesel-diesel-bioethanol blends. Energy \& Fuels, 25 (12), pp. 5767-5774. DOI: $10.1021 / \mathrm{ef2} 007936$

Berrang-Ford L., Ford J. D., Paterson J. (2011) Are we adapting to climate change?. Global Environmental Change, 21 (1), pp. 25-33. DOI: 10.1016/j.gloenvcha.2010.09.012

Beškovnik B., Twrdy E. (2012) Green logistics strategy for South East Europe: to improve intermodality and establish green transport corridors. Transport, 27 (1), pp. 25-33. DOI: $10.3846 / 16484142.2012 .663731$

Brooks N., Adger W. N., Kelly P. M. (2005) The determinants of vulnerability and adaptive capacity at the national level and the implications for adaptation. Global Environmental Change, 15 (2), pp. 151-163. DOI: 10.1016/j.gloenvcha.2004.12.006

Chollacoop N., Saisirirat P., Sukkasi S., Tongroon M., Fukuda T., Fukuda A., Nivitchanyong S. (2013) Potential of greenhouse gas emission reduction in Thai road transport by ethanol bus technology. Applied Energy, 102, pp. 112-123. DOI: 10.1016/j.apenergy.2012.07.039

Cséfalvay E., Akien G. R., Qi L., Horváth I. T. (2014) Definition and application of ethanol equivalent: Sustainability performance metrics for biomass conversion to carbon-based fuels and chemicals. Catalysis Today.

DOI: $10.1016 /$ j.cattod.2014.02.006

Csete M., Pálvölgyi T., Szendrö G. (2013) Assessment of climate change vulnerability of tourism in Hungary. Regional Environmental Change, 13 (5), pp. 1043-1057.

DOI: $\underline{10.1007 / \mathrm{s} 10113-013-0417-7}$

Dovers S. R., Hezri A. A., (2010) Institutions and policy processes: the means to the ends of adaptation. Wiley Interdiciplinary Reviews-Climate Change, 1 (2), pp. 212-231. DOI: $10.1002 / \mathrm{wcc} .29$

Easter C. (1999) Small States Development: A Commonwealth Vulnerability Index. The Round Table, 88 (351), pp. 403-422. DOI: $\underline{10.1080 / 003585399107947}$
Eisenack K., Stecker R., Reckien D., Hoffmann E. (2012) Adaptation to climate change in the transportsector: a review of actions and actors. Mitigation and Adaptation Strategies for Global Change, 17 (5), pp. 451-469.

DOI: $10.1007 / \mathrm{s} 11027-011-9336-4$

Etter A., McAlpine C. A., Seabrook L., Wilson K. A. (2011) Incorporating temporality and biophysical vulnerability to quantify the human spatial footprint on ecosystems. Biological Conservation, 144 (5), pp. 1585-1594

DOI: $10.1016 / \mathrm{j}$. biocon.2011.02.004

Füssel H-M. (2010) How inequitable is the global distribution of responsibility, capability, and vulnerability to climate change: A comprehensive indicator-based assessment. Global Environmental Change, 20 (4), pp. 597-611.

DOI: 10.1016/j.gloenvcha.2010.07.009

Haines A. (2012) Sustainable policies to improve health and prevent climate change. Social Science \& Medicine, 74 (5), pp. 680-683. DOI: 10.1016/j.socscimed.2011.12.008

Harvey M., Pilgrim S. (2011) The new competition for land: Food, energy, and climate change. Food Policy, 36 (1), pp. S40-S51.

DOI: 10.1016/j.foodpol.2010.11.009

Heltberg R., Siegel P. B., Jorgensen S. L. (2009) Addressing human vulnerability to climate change: Toward a 'no-regrets' approach. Global Environmental Change, 19 (1), pp. 89-99.

DOI: $10.1016 /$ j.gloenvcha.2008.11.003

Intergovernmental Panel on Climate Change (IPCC) (2007) IPCC Fourth Assessment Report: Climate Change 2007: Impacts, Adaptation and Vulnerability. Summary for Policy Makers. World Meteorological Organisation. Geneva.

Kaly U., Pratt C. (2000) Environmental vulnerability index: development and provisional indices and profiles for Fiji, Samoa, Tuvalu and Vanu$a t u$. Phase II report for NZODA. SOPAC Technical Report, 306, $89 \mathrm{p}$.

Kitano H. (2002) Systems biology: A Brief Overview. Science, 295 (5560), pp. $1662-1664$ DOI: $10.1126 /$ science. 1069492

Kivevele T., Mbarawa M., Bereczky Á., Zöldy M. (2011) Evaluation of the Oxidation Stability of Biodiesel Produced from Moringa oleifera Oil. Energy \& Fuels, 25 (11), pp. 5416-5421. DOI: $\underline{10.1021 / \mathrm{ef} 200855 \mathrm{~b}}$

Koetse M. J., Rietveld P. (2009) The impact of climate change and weather on transport: An overview of empirical findings. Transportation Research Part D: Transport and Environment, 14 (3), pp. 205-221. DOI: $10.1016 / j . \operatorname{trd} .2008 .12 .004$

Kriegler E., O’Neill B. C., Hallegatte S., Kram T., Lempert R. J., Moss R. H., Wilbanks T. (2012) The need for and use of socio-economic scenarios for climate change analysis: A new approach based on shared socio-economic pathways. Global Environmental Change, 22 (4), pp. 807-822.

DOI: $10.1016 /$ j.gloenvcha.2012.05.005

Kuchler M., Linnér B. (2012) Challenging the food vs. fuel dilemma: Genealogical analysis of the biofuel discourse pursued by international organizations. Food Policy, 37 (5), pp. 581-588. DOI: 10.1016/j.foodpol.2012.06.005 
Larsen R., Klocker S., Gerger A., Neil P. (2012) A framework for facilitating dialogue between policy planners and local climate change adaptation professionals: Cases from Sweden, Canada and Indonesia. Environmental Science \& Policy, 23, pp. 12-23.

DOI: $10.1016 /$ j.envsci.2012.06.014

Lebedevas S., Pukalskas S., Žaglinskis J., Matijošius J. (2012) Comparative investigations into energetic and ecological parameters of camelina-based biofuel used in the $1 Z$ diesel engine. Transport, 27 (2), pp. 171-177. DOI: $10.3846 / 16484142.2012 .694078$

O'Brien K., Leichenko R., Kelkar U., Venema H., Aandahl G., Tompkins H., Javed A., Bhadwal S., Barg S., Nygaard L., West J. (2004) Mapping vulnerability to multiple stressors: climate change and globalization in India. Global Environmental Change, 14 (4), pp. 303-313.

DOI: $10.1016 /$ j.gloenvcha.2004.01.001

O'Brien M., Holland T. D. (1992) The Role of Adaptation in Archeological Explanation. American Antiquity, 57 (1), pp. 36-69. DOI: $10.2307 / 2694834$

Pelling M., High C. (2005) Understanding adaptation: What can social capital offer assessments of adaptive capacity?. Global Environmental Change, 15 (4), pp. 308-309.

DOI: 10.1016/j.gloenvcha.2005.02.001

Pelling M., Uitto J. (2001) Small island developing states: natural disaster vulnerability and global change. Environmental Hazards, 3 (2), pp. 49-62. DOI: $10.1016 / \mathrm{S} 1464-2867(01) 00018-3$

Pérez-Martínez P. J. (2012) Energy consumption and emissions from the road Transport in Spain: a conceptual approach. Transport, 27 (4), pp. 383-396.

DOI: $10.3846 / 16484142.2012 .751051$

Pielke R. A. Jr. (1998) Rethinking the role of adaptation in climate policy. Global Environmental Change, 8 (2), pp. 159-170.

DOI: $10.1016 /$ S0959-3780(98)00011-9

Rao A. M., Rao K. R. (2012) Measuring urban traffic congestion $-a$ review. International Journal of Traffic and Transport Engineering, 2 (4), pp. 286-305. DOI: $10.7708 /$ ijtte.2012.2(4).01

Reyer C., Bachinger J., Bloch R., Hattermann F. F., Ibisch P. L., Kreft S., Lasch P., Lucht W., Nowicki C., Spathelf P., Stock M., Welp M. (2012) Climate change adaptation and sustainable regional development: a case study for the Federal State of Brandenburg, Germany. Regional Environmental Change, 12 (3), pp. 523-542. DOI: $10.1007 / \mathrm{s} 10113-011-0269-\mathrm{y}$

Romero-Lankao P. (2012) Governing Carbon and Climate in the Cities: An Overview of Policy and Planning Challenges and Options. European Planning Issues, 20 (1), pp. 7-26. DOI: $\underline{10.1080 / 09654313.2011 .638496}$
Scrieciu S., Barker T., Ackerman F. (2013) Pushing the boundaries of climate economics: critical issues to consider in climate policy analysis. Ecological Economics, 85, pp. 155-165. DOI: $\underline{10.1016 / \text { j.ecolecon.2011.10.016 }}$

Smit B., Wandel J. (2006) Adaptation, adaptive capacity and vulnerability. Global Environmental Change, 16 (2), pp. 282-292. DOI: $10.1016 /$ j.gloenvcha.2006.03.0

Szendrö G., Csete M., Török Á. (2012) Unbridgeable Gap Between Transport Policy and Practice in Hungary. Journal of Environmental Engineering And Landscape Management, 20 (2), pp. 104-109. DOI: $10.3846 / 16486897.2012 .660881$

Tanczos K., Molnar S., Torok A., Molnar M. (2011) Future trends in road transport systems in Hungary and in the EU. International Journal of Critical Infrastructures, 7 (2), pp. 163-175. DOI: $10.1504 / \mathrm{IJCIS} .2011 .041538$

Techner N., McDonald A., Foxon T. J., Paavola J. (2012) Integrated transitions toward sustainability: The case of water and energy policies in Israel. Technological Forecasting and Social Change, 79 (3), pp. $457-468$.

DOI: $10.1016 /$ j.techfore.2011.08.013

Tstovrsnik N., Morris M., Eckard R., O' Leary G., Pettit C., Fitzsimons P., Christy B., Sandall J., Soste L., Sposito, V. (2010) Victorian Climate Change Adaptation Program. [Online]

Available from: http://www.gtplantations.org/publication/view/test/.

Tubi A., Fischhendler I., Feitelson E. (2012) The effect of vulnerability on climate change mitigation policies. Global Environmental Change, 22 (2), pp. 472-482.

DOI: $10.1016 /$ j.gloenvcha.2012.02.004

Uhlik K., Szabados G., Török A. (2012) Elaboration of a Program to Facilitate the Implementation of the Directive 2009/33/EC on the Promotion of Clean and Energy-Efficient Road Motor Vehicles. International Journal for Traffic and Transport Engineering, 2 (3), pp. 170-177. DOI: $10.7708 /$ ijtte.2012.2(3).01

Vaiškūnaitè R., Mierauskas P., Špakauskas V. (2012) Biodiversity impact assessment in road development in Lithuania. Transport, 27 (2), pp. 187-195. DOI: $\underline{10.3846 / 16484142.2012 .695749}$

Vincent K. (2007) Uncertainty in adaptive capacity and the importance of scale. Global Environmental Change, 17 (1), pp. 12-24. DOI: $10.1016 /$ j.gloenvcha.2006.11.009

White Paper on Transport - Roadmap to a single European transport area - towards a competitive and resource-efficient transport system (2011) Directorate-General for Mobility and Transport. pp. 6-7.

Yeh S., Sperling D. (2010) Low carbon fuel standards: Implementation scenarios and challenges. Energy Policy, 38 (11), pp. 6955-6965. DOI: $10.1016 /$ j.enpol.2010.07.012 